\title{
Identification of a group 16SrIX 'Candidatus Phytoplasma phoenicium' phytoplasma associated with sweet orange exhibiting decline symptoms in Iran
}

\author{
Ali Abbasi ${ }^{1,2} \cdot$ Nader Hasanzadeh $^{2} \cdot$ Maryam Ghayeb Zamharir $^{1}$ (D) Masoud Tohidfar $^{3}$
}

Received: 12 February 2019 / Accepted: 15 April 2019 / Published online: 4 May 2019

(C) Australasian Plant Pathology Society Inc. 2019

\begin{abstract}
During a survey in an orange (Citrus sinensis) garden in the south of the Kerman province of Iran, some trees were observed showing symptoms of yellowing and decline. Nested PCR analysis using phytoplasma universal primers identified symptomatic samples as phytoplasma-positive, whereas the symptomless samples gave no PCR products. Sequence similarity and phylogenetic studies using 16S rRNA gene sequences demonstrated that the sweet orange decline associated phytoplasma belongs to the 16SrIX 'Candidatus Phytoplasma phoenicium' group. To the best of the authors' knowledge this is the first report of association of a phytoplasma belonging to the 'Candidatus Phytoplasma phoenicium' group with decline symptoms in sweet orange in Iran.
\end{abstract}

Keywords Iran $\cdot$ Phytoplasma $\cdot$ Yellows $\cdot$ Decline $\cdot$ Sweet orange

Field surveys in recent years have revealed the presence of a significant number of citrus trees showing disease symptoms including leaf yellows, little leaf, leaf defoliation and sudden decline in summer. In China, phytoplasmas related to 'Candidatus Phytoplasma asteris' have been identified in sweet orange, pomelo and mandarin with greening (Huanglongbing (HLB))-like symptoms (Chen et al. 2009) and related to the peanut witches' broom (16SrII) phytoplasma group in grapefruit with similar symptoms (Lou et al. 2013). A phytoplasma from the peanut witches' broom (16SrII) group has also been found associated with HLB symptoms in sweet orange and lime in Iran (Saberi et al. 2017) and in 2019, it was reported that 'Candidatus Liberibacter asiaticus' and 'Candidatus Phytoplasma aurantifolia' (16SrII) related strains are associated with a new citrus decline disease (CDD) in Iran (Passera et al. 2018). However, the symptoms observed in this present study

Maryam Ghayeb Zamharir

zamharir2005@yahoo.com

1 Plant Diseases Department, Iranian Research Institute of Plant protection, Agricultural Research, Education and Extension Organization (AREEO), Tehran, Iran

2 Department of Plant Protection, College of Agricultural Sciences and Food Industries, Science and Research Branch, Islamic Azad University, Tehran, Iran

3 Biotechnology group, Department of New Technology and Energy Engineer, Shahid Beheshti University, Tehran, Iran differ from those reported previously for HLB. Here, the fruits of symptomatic trees did have not HLB fruit symptoms, and molecular analysis did not indicate infection of these samples with 'Candidatus Liberibacter asiaticus', Spiroplasma citri or citrus tristeza virus and the leaves of infected trees showed severe yellows. In this article, the phytoplasma associated with these yellowing and decline symptom in sweet orange in Iran has been identified.

A total of 84 leaf samples were collected in 2016 and 2017 from 74 symptomatic and 10 symptomless sweet orange plants (cultivars Valencia, and navel) in orchards and domestic gardens located in the south of Kerman province, Iran. Symptomless leaves from the same sweet orange cultivars grown in a greenhouse were used as the healthy control samples.

The specimens from sweet orange plants showing decline symptoms in the garden were grafted onto healthy trees that have been tested for major sieve tube pathogens, and the specimens from healthy sweet orange trees were grafted to other healthy trees as a control in greenhouse conditions. The grafted plants were tested for phytoplasma infections as described below, 6 months after grafting.

Total DNA was extracted from $0.1 \mathrm{~g}$ of leaf samples according to previously described protocols (Doyle and Doyle 1987). Two universal phytoplasma nested primer sets P1/Tint (Smart et al. 1996; Deng and Hiruki 1991) and R16F2n/ R16R2 (Gundersen and Lee 1996) were used for direct and nested PCR. Almond witches' broom phytoplasma (16SrIX- 

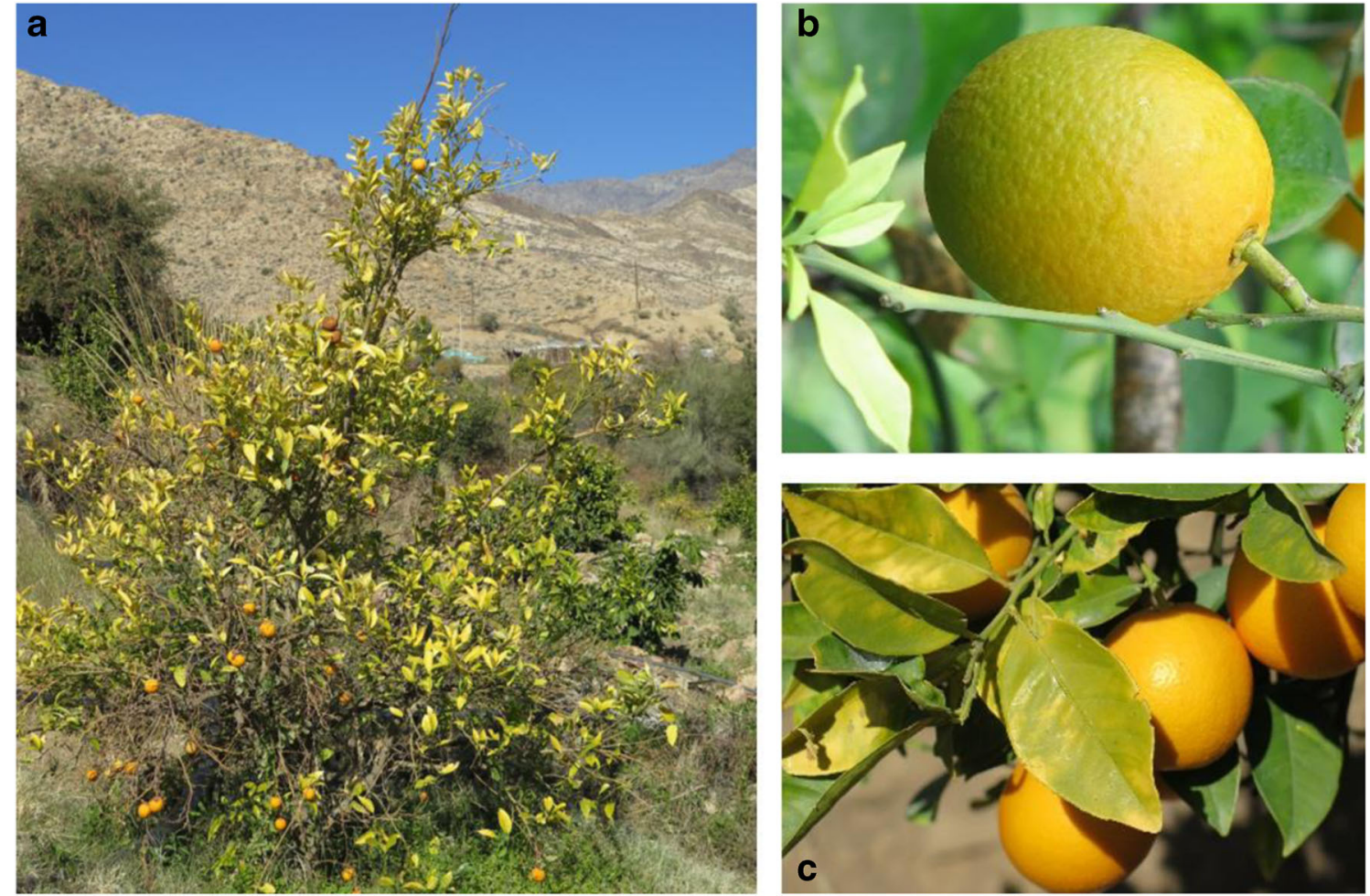

Fig. 1 Sweet orange decline symptoms on (a) a tree in the garden; (b) HLB symptoms on infected fruit; (c) sweet orange decline phytoplasma on infected fruits

B) was used as a standard positive controls in molecular analyses in this study. The PCR products were analyzed in $1.2 \%$ agarose gels in TAE buffer.

Positive PCR products that were amplified from 5 sweet orange trees from different orchards, using R16F2n/R2 primers in nested PCR were sequenced directly. The sequences obtained were assembled, aligned and compared with nucleotide sequences in the GenBank database, using BLAST (NCBI, Bethesda, MD, USA). Phylogenetic analyses were performed with maximum parsimony (MP) analysis by using
16S rDNA sequences from sweet orange samples SO84, SO47, SO18, SO24 and SO65 and from 56 'Candidatus phytoplasma' reference strains (Wei et al. 2007), using Bacillus subtilis as the outgroup. The analysis was replicated 1000 times (Tamura et al. 2004).

All samples showing decline symptoms (Fig. 1) resulted in positive nested PCR amplification with the R16F2n/R2 primers. No amplification was obtained from the negative controls without DNA template and from the symptomless sweet orange samples. Results of grafting in two sweet orange
Fig. 2 Grafted sweet orange (1: native type and 2: Valencia cultivar) showing disease symptoms 8 month after grafting and healthy Valencia (right)

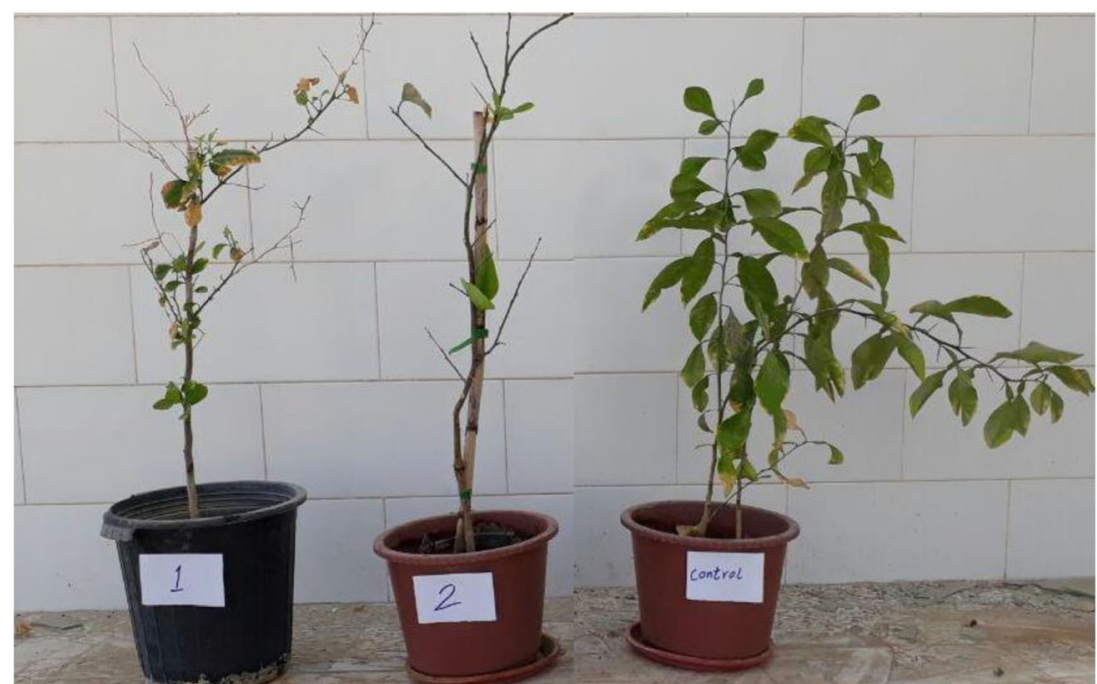




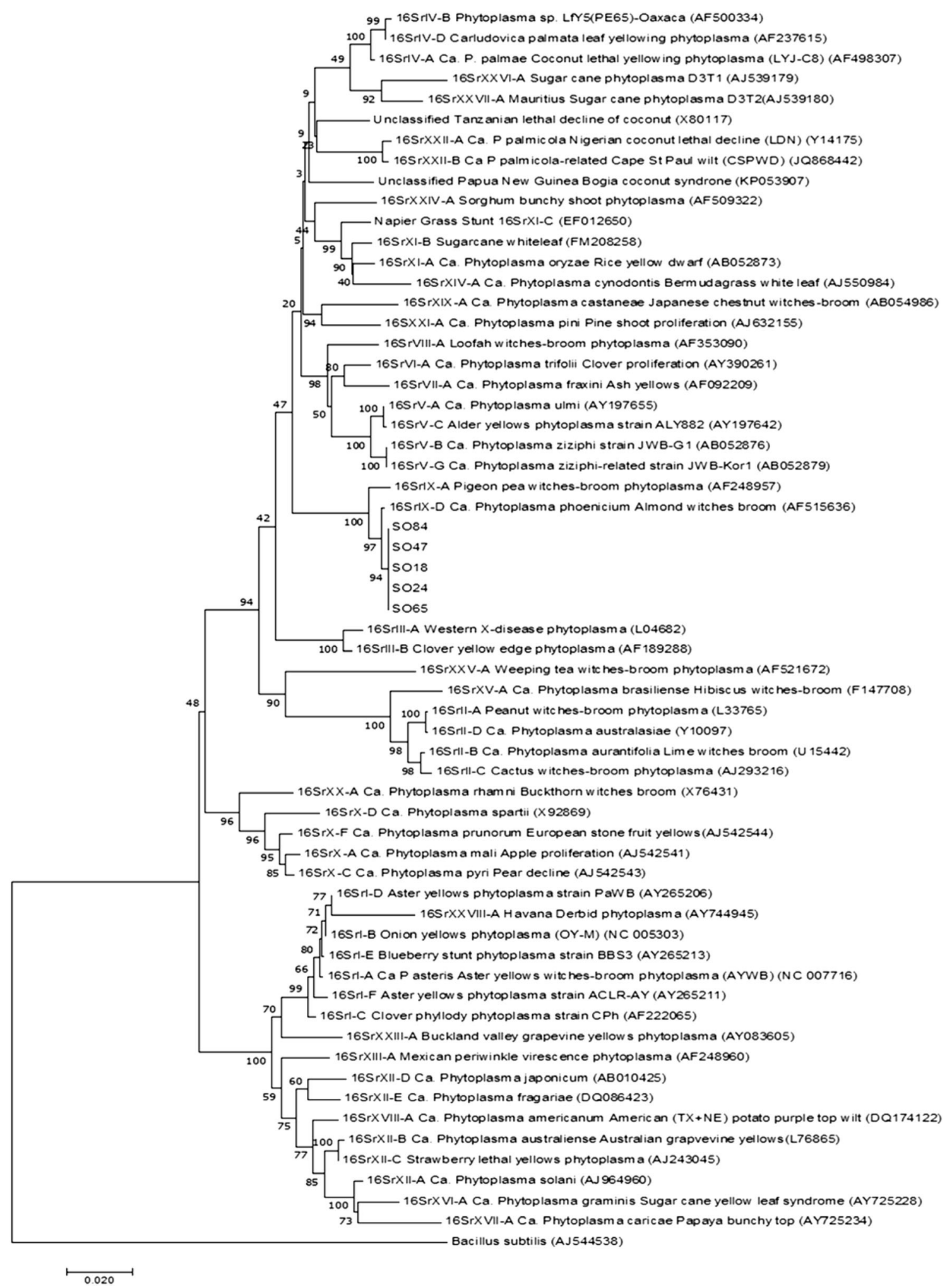

Fig. 3 Phylogenetic tree using the Maximum parsimony method on 16S rRNA sequences of representative 'Candidatus Phytoplasma' species with the sweet orange decline phytoplasma sequences (SO84, SO47, $\mathrm{SO} 18, \mathrm{SO} 24$ and SO65), indicating their presence in the ' $\mathrm{Ca}$.

cultivars (1: native type and 2: Valencia) with 5 replicates showed that disease symptoms appear in graft-inoculated
Phytoplasma phoenicium' 16SrIX-B/16SrIX-D grouping. Accession numbers are shown in brackets and Bacillus subtilis was used as the outgroup

plants 8 month after grafting (Fig. 2) and phytoplasma infections were confirmed using nested PCR analysis. 
The sequences of the selected strains $\mathrm{SO} 84, \mathrm{SO} 47, \mathrm{SO} 18$, SO24 and SO65 have been deposited in GenBank (NCBI) with accession numbers SAMN10409248, SAMN10409249, SAMN10409250, SAMN10409251 and SAMN10409252 respectively. The BLAST analysis showed all the 5 phytoplasma 16S rDNA sequences from the present study had 99\% homology with 'Prunus scoparia' witches'-broom phytoplasma isolate Seerjan (accession number KM235729) (Salehi et al. 2015). The obtained aligned sequences of the sweet orange decline phytoplasma strains were classified into the 16SrIX-B/ 16SrIX-D group, also referred to as 'Candidatus Phytoplasma phoenicium' (Fig. 3).

It has been reported before that there is genetic diversity among ' $\mathrm{Ca}$. Phytoplasma phoenicium' strains (Barbosa et al. 2012; Lova et al. 2011), which could be related to different ecological or climatic niches of the phytoplasma populations. The sweet orange decline phytoplasma could be transmitted to other citrus species from external sources of inocula, which could include crop plants, ornamental plants or weeds, but correlation studies of sweet orange decline phytoplasma strains with symptom specificity, efficiency, severity and the vector transmission of strains should be performed in future studies in Iran.

\section{Compliance with ethical standards}

Funding This study has not received any funding.

Conflict of interest The authors declare that they have no conflict of interest.

Ethical approval This article does not contain any studies with human participants or animals performed by any of the authors.

\section{References}

Barbosa JC, Eckstein B, Filho AB, Bedendo IP, Kitajima EW (2012) Molecular characterization of a phytoplasma of group 16SrIX related to 'ca. Phytoplasma phoenicium' in periwinkle in Brazil. Trop Plant Pathol 37:130-135
Chen J, Pu X, Deng X, Liu S, Li H, Civerolo E (2009) A phytoplasma related to 'Candidatus Phytoplasma asteris' detected in citrus showing huanglongbing (yellow shoot disease) symptoms in Guangdong, P. R. China. Phytopathology 99:236-242

Deng S, Hiruki C (1991) Amplification of 16S rRNA genes from culturable and nonculturable Mollicutes. J Microbiol Methods 14: $53-61$

Doyle JJ, Doyle JL (1987) A rapid DNA isolation procedure for small quantities of fresh leaf tissue. Phytochem Bull 19:11-15

Gundersen DE, Lee IM (1996) Ultrasensitive detection of phytoplasmas by nested-PCR assays using two universal primer pairs. Phytopathol Mediterr 35:144-151

Lou B, Bai X, Bai Y, Deng C, Chowdhury MR, Chen C, Song Y (2013) Detection and molecular characterization of a 16SrII-A phytoplasma in grapefruit (Citrus paradisi) with Huanglongbing-like symptoms in China. J Phytopathol 162:387-395

Lova MM, Quaglino F, Abou-Jawdah Y, Choueiri E, Sobh H, Casati P, Tedeschi R, Alma A, Bianco PA (2011) Identification of new 16SrIX subgroups, $-\mathrm{F}$ and $-\mathrm{G}$, among 'Candidatus Phytoplasma phoenicium' strains infecting almond, peach and nectarine in Lebanon. Phytopathol Mediterr 50:273-282

Passera A, Alizadeh H, Azadvar M, Quaglino F, Alizadeh A, Casati P, Bianco PA (2018) Studies of microbiota dynamics reveals association of "Candidatus Liberibacter asiaticus" infection with Citrus (Citrus sinensis) decline in the south of Iran. Int J Mol Sci 19: $1817-1838$

Saberi E, Alavi SM, Safaie N, Moslemkhany C, Azadvar M (2017) Bacterial pathogens associated with citrus huanglongbing-like symptoms in southern Iran. J Crop Prot 6:99-113

Salehi M, Salehi E, Abbasian M, Izadpanah K (2015) Wild almond (Prunus scoparia), a potential source of almond witches' broom phytoplasma in Iran. J Plant Pathol 97:99-103

Smart CD, Schneider B, Blomquist CL, Guerra LJ, Harrison NA, Ahrens U, Lorenz KH, Seemüller E, Kirkpatrick BC (1996) Phytoplasmaspecific PCR primers based on sequences of the 16-23S rRNA spacer region. Appl Environ Microbiol 62:2988-2993

Tamura K, Nei M, Kumar S (2004) Prospects for inferring very large phylogenies by using the neighbor-joining method. Proc Natl Acad Sci U S A 101:11030-11035

Wei W, Davis RE, Lee M, Zhao Y (2007) Computer-simulated RFLP analysis of 16SrRNA genes: identification of ten new phytoplasma groups. Int J Syst Evol Microbiol 57:1855-1867 